\title{
The acute phase of inflammatory response involved in the wound-healing process after excimer laser treatment
}

This article was published in the following Dove Press journal:

Clinical Ophthalmology

30 May 2016

Number of times this article has been viewed

\author{
Mirko Resan ${ }^{1,2}$ \\ Miroslav Vukosavljevic ${ }^{1,2}$ \\ Danilo Vojvodic ${ }^{2,3}$ \\ Brigitte Pajic-Eggspuehler ${ }^{4}$ \\ Bojan Pajic ${ }^{2,4-6}$ \\ 'Eye Clinic, Military Medical Academy, \\ Belgrade, Serbia; ${ }^{2}$ Faculty of Medicine \\ of the Military Medical Academy, \\ University of Defense, Belgrade, \\ Serbia; ${ }^{3}$ Department for Clinical \\ and Experimental Immunology, \\ Institute for Medical Research, \\ Military Medical Academy, Belgrade, \\ Serbia; ${ }^{4}$ Eye Clinic ORASIS, Swiss Eye \\ Research Foundation, Reinach AG, \\ Switzerland; ${ }^{5}$ Department of Physics, \\ Faculty of Science, University of \\ Novi Sad, Novi Sad, Serbia; ${ }^{6}$ Division \\ of Ophthalmology, Department of \\ Clinical Neurosciences, University \\ Hospitals of Geneva, Switzerland
}

Correspondence: Bojan Pajic Eye Clinic ORASIS, Swiss Eye Research Foundation, Titlisstrasse 44, 5734 Reinach, Switzerland

Tel +4I 627656080

Email bpajic@datacomm.ch
Purpose: To evaluate the participation of proinflammatory cytokines in the acute phase of corneal wound-healing response after excimer laser treatment.

Methods: The study included 68 myopic eyes up to -3.0 diopters divided into two groups: 1) eyes treated with laser in situ keratomileusis (LASIK) $(n=31)$ and 2) eyes treated with photorefractive keratectomy (PRK) $(n=37)$. Each group was then divided into three subgroups based on tear sampling times: before ( 0 hours), 1 hour after, and 24 hours after treatment. The tear fluid was sampled from lower lateral tear meniscus using a cellulose microsurgical sponge. The levels of tumor necrosis factor- $\alpha$ (TNF- $\alpha$ ), interleukin (IL)-1 $\beta$, IL-6, and IL- 8 in tear fluid were determined by flow cytometry method.

Results: Statistical significance was observed in the concentrations of TNF- $\alpha$ ( $P=0.0421)$ and IL-1 $\beta(P=0.0225)$ between samples collected 1 and 24 hours after PRK treatment in favor of samples collected 1 hour after treatment. IL-6 concentration changes showed a significant increase in the PRK group in both time intervals following treatment compared to pretreatment ( 0 hour $/ 1$ hour, $P=0.0031 ; 0$ hour 24 hours, $P=0.0059$ ). For IL- 8 concentrations, significant differences were observed between control and experimental groups in samples collected 1 hour after LASIK and 1 hour after PRK treatment ( $P<0.001$ for both groups), and IL- 8 concentrations between control and experimental groups in samples collected 24 hours after LASIK and 24 hours after PRK treatment were greater after PRK treatment $(P=0.0005)$. Comparison of average concentration values of proinflammatory cytokines in all the tested samples between LASIK and PRK groups showed significantly higher levels of IL-1 $\beta$ in the LASIK group 24 hours after treatment $(P=0.0134)$, and of IL-6 in the PRK group 24 hours after treatment $(P=0.0031)$.

Conclusion: The acute phase of corneal wound healing after excimer laser treatment is defined by an intensive inflammatory response. After PRK treatment, there were increased concentrations of TNF- $\alpha$ and IL- $1 \beta$ in tear samples 1 hour after treatment, IL-6, 1 and 24 hours after treatment, and IL-8, 1 and 24 hours after treatment. After LASIK treatment, there were increased concentrations of IL- 8 in tear samples 1 hour after treatment and IL-1 $\beta, 24$ hours after treatment. Both PRK and LASIK methods are characterized with a significant inflammatory response. However, tear findings following PRK method showed more intensive inflammatory response than the findings after LASIK method.

Keywords: LASIK, PRK, tears, proinflammatory cytokines, wound healing

\section{Introduction}

LASIK (laser in situ keratomileusis) and PRK (photorefractive keratectomy) are the two most frequently used refractive surgical methods. Both methods involve excimer laser treatments that result in photoablative effects to correct existing 
ametropia and lead to surgically induced trauma. This trauma responds with a complex cascade of cellular interactions mediated by cytokines, growth factors, and chemokines. ${ }^{1}$ This response is intertwined by interactions of epithelial, stromal, neural, lacrimal, and immune system cells and determines the efficiency and safety of these methods. ${ }^{2}$

In PRK, energy from an excimer laser is applied directly on deepithelized stroma. During the wound-healing response, corneas treated with PRK may rarely react in subepithelial haze. The main cause of this haze is an interaction between the epithelium and stromal keratocytes which is mediated by cytokines and which activates keratocytes and causes degradation of the stromal extracellular matrix. In LASIK, energy from an excimer laser is applied into deeper layers of the stroma that is at a greater distance from epithelium. In comparison with PRK, the wound-healing response after LASIK is featured by a weaker interaction between epithelium and stromal keratocytes because the epithelial surface generally stays intact in LASIK. ${ }^{3}$

Apoptosis of keratocytes is the earliest event in the corneal wound-healing cascade after excimer laser treatment, followed by epithelial mitosis and migration, necrosis of stromal cells, keratocytes proliferation, myofibroblast production, collagen deposition, and inflammatory cell infiltration. Over a period of several months, the cornea returns to a state similar to its original form, ie, before the treatment. ${ }^{4,5}$ The cascade is triggered with an epithelial injury, and the intensity of the response is proportional to the degree of epithelial injury. For this reason, many events included in the corneal wound-healing response are more intense after PRK than after LASIK. Wounded epithelial cells release more proinflammatory cytokines that ligate with specific receptors on stromal cells and modulate processes such as apoptosis of keratocytes, fibroblast proliferation, myofibroblast production, and inflammatory cell infiltration. After LASIK, epithelial trauma is significantly reduced, compared to PRK, and tends to be confined to the flap edge. ${ }^{6}$

The production of interleukin (IL)-1 as a result of epithelial injury initiates the earliest phase of the corneal wound-healing cascade for both LASIK and PRK. ${ }^{4}$ For this reason, it would be interesting to examine the participation of other proinflammatory cytokines (tumor necrosis factor- $\alpha$ [TNF- $\alpha]$, IL-6, and IL-8) during this same phase of corneal wound healing. Proinflammatory cytokines are produced by different ocular surface cells: Langerhans cells produce IL-1; macrophages produce IL-1, IL-6, and TNF; mast cells produce IL-6; conjunctival epithelial cells produce IL-1, IL-6, and IL-8; corneal epithelial cells produce IL-1, IL-6, and IL-8; keratocytes produce IL-1, IL-6, and IL-8; fibroblasts produce IL-1, IL-6, and IL-8; and vascular endothelial cells produce IL-6 and IL-8. ${ }^{7}$ Controlled inflammation is useful because it acts as a normal tissue injury response and eventually leads to the renewal of tissue structure and function. Cytokines, which are released during inflammation, determine the type and the intensity of response. IL- $1 \beta$ and TNF- $\alpha$ are expressed during the early-onset phase of acute inflammation. ${ }^{8,9}$

The objective of this study was to determine and compare the levels of proinflammatory cytokines (TNF- $\alpha$, IL-1 $\beta$, IL-6, and IL-8) in tears before and after LASIK and PRK treatment during the acute phase of the inflammatory response which is involved in the wound-healing process after excimer laser treatment.

\section{Materials and methods}

With approval from the Ethical Board of the Military Medical Academy in Belgrade, Serbia, a clinical, randomized, prospective cohort study was conducted in accordance with the Declaration of Helsinki. Written informed consent was obtained from all the participants. The study included 68 myopic eyes up to -3.0 diopter sphere, ie, 204 samples of tears (three samples were taken from each eye), which were divided into two groups based on the type of excimer laser intervention performed: Group 1, eyes treated with LASIK $(n=31)$ and Group 2, eyes treated with PRK $(n=37)$.

Each group was then divided into three subgroups which were formed based on the tear sampling times, which means that tear samples were taken from each eye at the following times: before treatment ( 0 hours, control group), 1 hour after treatment, and 24 hours after treatment. The following are the subgroups and sample numbers:

- Before LASIK treatment (0 hours, control group) (31 tear samples)

- 1 hour after LASIK treatment (31 tear samples)

- 24 hours after LASIK treatment (31 tear samples)

- Before PRK treatment (0 hours, control group) (37 tear samples)

- 1 hour after PRK treatment (37 tear samples)

- 24 hours after PRK treatment (37 tear samples).

Thirty-five participants were included in the study with 68 eyes being treated (two participants had one eye operated). There was a total of 16 participants in the LASIK group (nine men and seven women), and a total of 19 participants in the PRK group (14 men and five women). The participants 
did not use anti-inflammatory therapy 24 hours after the intervention and had no general or eye disorders.

A Wavelight Allegretto (400 Hz) excimer laser was used to perform photoablation. During LASIK, a Moria microkeratome (One Use-Plus SBK, Moria, France) was used to create a flap, and for PRK we removed the corneal epithelium with an Amoils rotational brush.

A method described in the study by Acera et $\mathrm{al}^{10}$ was applied to collect the tear samples. Tear fluid was collected from lower lateral tear meniscus with minimal irritation of ocular surface and the edge of eyelids, with no use of anesthetics. Each tear sample was taken by using a cellulose microsurgical sponge (MicroSponge ${ }^{\mathrm{TM}}$ regular tip; Alcon, Inc., Hünenberg, Switzerland). After sampling, the tear fluid was separated by centrifugation of the sponge in $0.5 \mathrm{~mL}$ of phosphate buffered saline. The samples were centrifuged at $13,000 \mathrm{rpm}$ for 15 minutes at $4^{\circ} \mathrm{C}$ (MPW-350r; MED Instruments, Warszawa, Poland). Collected samples were kept at $-80^{\circ} \mathrm{C}$ until the final analysis.

The levels of TNF- $\alpha$, IL-1 $\beta$, IL-6, and IL-8 in tear fluid were determined by flow cytometry method using the Beckman Coulter FC 500 flow cytometer with CXP analysis software, and we used the commercial test kit (Human Th1/ Th2 11 plex FlowCytomix Multiplex; Bender MedSystem, Vienna, Austria) intended for cytokine detection with a small sample volume.

Statistical data were processed with methods of descriptive and inferential statistics: mean, standard deviation, maximum and minimum range, mode, and median for descriptive statistics, and Wilcoxon signed-rank test and Mann-Whitney test for inferential statistics.

\section{Results}

The average age of the participants in the LASIK and PRK groups was 34 years $(33.81 \pm 6.52)$ and 33 years $(33.05 \pm 6.11)$, respectively.

Table 1 presents the concentrations of TNF- $\alpha$, IL- $1 \beta$, IL-6, and IL-8 (pg/mL) in tear samples (with mean values and standard deviation) collected from the participants treated with LASIK and PRK methods at different time points.

Figure 1 shows the percentages of samples with detectable concentrations of proinflammatory cytokines (TNF- $\alpha$, IL-1 $\beta$, IL-6, and IL-8) in tear samples collected: before (0 hours), 1 hour after, and 24 hours after LASIK treatment. Figure 2 shows the percentages of samples with detectable concentrations of proinflammatory cytokines (TNF- $\alpha$, IL-1 $\beta$, IL-6, and IL-8) in tear samples collected: before ( 0 hours), 1 hour after, and 24 hours after PRK treatment.
Statistically significant differences in the concentrations of proinflammatory cytokines (TNF- $\alpha$, IL-1 $\beta$, IL-6, and IL-8) in tear samples with detectable cytokine values collected before treatment ( 0 hours, control), 1 hour after treatment, and 24 hours after treatment by LASIK and PRK methods are shown in Table 2 . Statistically significant differences were noted in concentrations of TNF- $\alpha(P=0.0421)$ and IL-1 $\beta(P=0.0225)$ between samples collected 1 and 24 hours after PRK treatment in favor of samples collected 1 hour after treatment. IL-6 concentration changes showed a significant increment (statistically significant difference at the level $P<0.01$ ) in PRK-treated participants in both time intervals after treatment compared to pretreatment ( 0 hour 11 hour, $P=0.0031 ; 0$ hour $/ 24$ hours, $P=0.0059$ ). Both PRK and LASIK groups demonstrated statistically significant $(P<0.001)$ differences in concentration changes of IL-8 between control and experimental samples collected 1 hour after treatment. Even greater differences were observed between control and experimental samples collected 24 hours after LASIK and PRK treatments $(P=0.0005)$. Results in Table 2 demonstrate a larger change of IL-6 and IL-8 concentrations in tear samples after PRK treatment than after LASIK treatment.

Comparisons of average proinflammatory cytokine concentrations in all the tested samples between the two treatment groups showed significantly higher levels of IL-1 $\beta$ in the LASIK group 24 hours after treatment $(P=0.0134)$ and IL-6 in the PRK group 24 hours after treatment $(P=0.0031)$ (Table 3).

Dynamics of concentration changes for each proinflammatory cytokine between tear samples collected before, 1 hour after, and 24 hours after treatment with LASIK and PRK (only samples with detectable cytokines) showed that all proinflammatory cytokines (TNF- $\alpha$, IL-1 $\beta$, IL-6, and IL-8) exhibited concentration changes in such dynamics that the number of samples with increased concentrations was much larger than the number of samples with decreased concentrations 1 hour after treatment in both the LASIK and PRK groups. Another striking feature of this study is the comparison of samples 24 hours after treatment with control samples in both the LASIK and PRK groups, where we obtained significantly larger number of samples with increased concentrations of IL-6 and IL-8 than the number of samples with decreased concentrations of these cytokines. It is also significant for IL-1 $\beta$ that by comparing the samples 24 hours after treatment with the control samples in the LASIK group, we obtained a larger number of samples with increased concentrations than 
Table I The concentrations of TNF- $\alpha$, IL-I $\beta$, IL-6, and IL-8 (pg/mL) in tear samples (with mean values and standard deviation) from the participants treated with LASIK and PRK methods at different time points

\begin{tabular}{|c|c|c|c|c|c|c|c|c|c|c|c|c|}
\hline \multirow[t]{2}{*}{ ID } & \multicolumn{3}{|l|}{ TNF- $\alpha$} & \multicolumn{3}{|l|}{ IL-I $\beta$} & \multicolumn{3}{|l|}{ IL-6 } & \multicolumn{3}{|l|}{ IL-8 } \\
\hline & $\mathbf{O h}$ & I h & $24 \mathrm{~h}$ & $\mathbf{O h}$ & I h & $24 \mathrm{~h}$ & $\mathbf{O h}$ & I h & $24 \mathrm{~h}$ & $\mathbf{O ~ h}$ & I h & $24 \mathrm{~h}$ \\
\hline \multicolumn{13}{|l|}{ LASIK } \\
\hline 34 & 0.00 & 0.00 & 0.00 & 0.00 & 0.00 & 0.00 & 0.00 & 0.00 & 0.00 & 0.00 & 0.00 & 0.00 \\
\hline 35 & 0.00 & 0.00 & 0.00 & 0.00 & 0.00 & 1.12 & 0.00 & 0.00 & 0.00 & 0.00 & 0.00 & 0.00 \\
\hline 40 & 0.00 & 94.88 & 0.00 & 0.00 & 89.40 & 5.71 & 0.00 & 17.13 & 0.00 & 0.00 & 52.12 & 0.00 \\
\hline $4 I$ & 0.00 & 91.89 & 0.00 & 0.00 & 92.01 & 0.00 & 0.00 & 15.20 & 0.00 & 0.00 & 53.26 & 0.00 \\
\hline 42 & 51.27 & 63.52 & 45.23 & 18.80 & 5.08 & 4.06 & 0.00 & 9.32 & 0.00 & 36.50 & 37.65 & 43.44 \\
\hline 43 & 0.00 & 48.25 & 0.00 & 6.77 & 7.43 & 6.34 & 0.00 & 0.00 & 0.00 & 0.00 & 41.43 & 34.47 \\
\hline 44 & 83.81 & 39.25 & 0.00 & 8.96 & 4.46 & 0.00 & 0.63 & 0.00 & 0.00 & 42.28 & 0.00 & 0.00 \\
\hline 45 & 0.00 & 83.98 & 0.00 & 2.66 & 8.07 & 4.06 & 0.00 & 0.00 & 0.00 & 0.00 & 43.14 & 42.85 \\
\hline 46 & 0.00 & 0.00 & 0.00 & 0.00 & 4.67 & 0.00 & 0.00 & 0.00 & 0.00 & 0.00 & 0.00 & 0.00 \\
\hline 47 & 0.00 & 0.00 & 0.00 & 0.00 & 0.00 & 0.00 & 0.00 & 0.00 & 0.00 & 0.00 & 35.93 & 50.11 \\
\hline 48 & 0.00 & 0.00 & 0.00 & 0.00 & 0.00 & 0.00 & 0.00 & 0.00 & 0.00 & 0.00 & 39.97 & 0.00 \\
\hline 49 & 0.00 & 0.00 & 0.00 & 0.00 & 5.50 & 0.00 & 0.00 & 10.75 & 0.00 & 0.00 & 57.70 & 0.00 \\
\hline 50 & 0.00 & 0.00 & 0.00 & 0.00 & 0.56 & 0.00 & 0.00 & 0.63 & 0.00 & 0.00 & 45.90 & 0.00 \\
\hline 51 & 0.00 & 0.00 & 0.00 & 0.00 & 0.00 & 0.00 & 0.00 & 0.00 & 0.00 & 0.00 & 0.00 & 0.00 \\
\hline 52 & 0.00 & 0.00 & 39.25 & 0.00 & 0.00 & 4.26 & 0.00 & 0.00 & 0.00 & 0.00 & 0.00 & 0.00 \\
\hline 53 & 98.06 & 106.15 & 95.84 & 25.62 & 97.06 & 92.95 & 14.07 & 27.44 & 14.92 & 49.76 & 56.86 & 58.13 \\
\hline 54 & 85.37 & 0.00 & 0.00 & 14.16 & 6.99 & 3.86 & 0.00 & 0.00 & 0.00 & 42.42 & 38.81 & 0.00 \\
\hline 55 & 82.63 & 87.56 & 120.88 & 20.44 & 8.97 & 105.11 & 0.00 & 0.00 & 87.12 & 36.50 & 39.97 & 76.06 \\
\hline 56 & 94.01 & 39.25 & 83.99 & 89.15 & 7.85 & 21.55 & $|8.3|$ & 0.00 & 0.00 & 47.86 & 38.81 & 47.86 \\
\hline 57 & 0.00 & 0.00 & 0.00 & 3.45 & 0.00 & 0.00 & 0.00 & 0.00 & 0.70 & 0.00 & 0.00 & 53.64 \\
\hline 58 & 0.00 & 0.00 & 0.00 & 0.00 & 0.00 & 11.50 & 0.00 & 0.00 & 0.00 & 0.00 & 0.00 & 55.02 \\
\hline 59 & 0.00 & 48.25 & 84.86 & 0.00 & 1.50 & 8.07 & 0.00 & 0.00 & 3.64 & 0.00 & 41.29 & 143.96 \\
\hline 60 & 0.00 & 0.00 & 83.99 & 0.00 & 1.88 & 17.21 & 0.00 & 0.00 & 0.00 & 0.00 & 0.00 & 90.04 \\
\hline 61 & 60.44 & 121.32 & 101.56 & 93.55 & 121.40 & 92.18 & 87.59 & 111.79 & 99.01 & 41.15 & 84.51 & 74.36 \\
\hline 62 & 86.64 & 82.97 & 89.52 & 14.40 & 18.00 & 21.55 & 7.23 & 22.36 & 17.76 & $4 I .71$ & 58.56 & 76.94 \\
\hline 63 & 0.00 & 94.01 & 0.00 & 0.00 & 22.12 & 0.00 & 0.00 & 17.52 & 0.00 & 0.00 & 49.23 & 41.15 \\
\hline 64 & 0.00 & 0.00 & 0.00 & 0.00 & 0.00 & 0.00 & 0.00 & 0.00 & 0.00 & 0.00 & 35.37 & 67.02 \\
\hline 65 & 0.00 & 0.00 & 0.00 & 0.00 & 0.00 & 0.00 & 0.00 & 0.00 & 0.00 & 0.00 & 53.45 & 0.00 \\
\hline 66 & 0.00 & 0.00 & 0.00 & 0.00 & 0.00 & 1.88 & 0.00 & 0.00 & 0.00 & 0.00 & 39.97 & 43.14 \\
\hline 67 & 0.00 & 51.27 & 42.24 & 0.00 & 11.50 & 10.79 & 0.00 & 0.00 & 0.00 & 0.00 & 47.86 & 44.80 \\
\hline 68 & 0.00 & 0.00 & 0.00 & 0.00 & 0.00 & 2.27 & 0.00 & 0.00 & 0.00 & 0.00 & 0.00 & 0.00 \\
\hline Mean \pm & $20.72 \pm$ & $33.95 \pm$ & $25.40 \pm$ & $9.61 \pm$ & $16.60 \pm$ & $13.37 \pm$ & 4.12士 & $7.49 \pm$ & $7.20 \pm$ & $10.90 \pm$ & $31.98 \pm$ & $33.64 \pm$ \\
\hline SD & 36.55 & 41.85 & 40.33 & 22.96 & 33.39 & 28.48 & 16.05 & 20.85 & 23.34 & 18.94 & 24.28 & 36.53 \\
\hline \multicolumn{13}{|l|}{ PRK } \\
\hline I & 0.00 & 0.00 & 0.00 & 0.00 & 3.25 & 0.00 & 0.00 & 0.00 & 12.61 & 0.00 & $4 \mid .71$ & 57.28 \\
\hline 2 & 0.00 & 0.00 & 0.00 & 0.00 & 0.00 & 0.00 & 0.00 & 0.00 & 18.90 & 0.00 & 0.00 & 52.87 \\
\hline 3 & 0.00 & 0.00 & 0.00 & 0.00 & 0.00 & 0.00 & 0.00 & 0.00 & 0.00 & 0.00 & 0.00 & 0.00 \\
\hline 4 & 0.00 & 82.63 & 0.00 & 0.00 & 3.06 & 4.26 & 0.00 & 3.85 & 2.63 & 0.00 & 41.57 & 51.01 \\
\hline 5 & 91.48 & 104.53 & 0.00 & 88.93 & 95.47 & 0.00 & 11.12 & $|8.3|$ & 27.44 & 46.22 & 57.70 & 36.11 \\
\hline 6 & 87.75 & 95.32 & 0.00 & 25.61 & 94.09 & 0.00 & 4.52 & $25.7 \mid$ & 21.38 & 43.59 & 55.83 & 51.01 \\
\hline 7 & 57.40 & 82.80 & 119.52 & 8.74 & 15.66 & 110.02 & 0.00 & 3.52 & 91.95 & 41.15 & 47.36 & 84.51 \\
\hline 8 & 0.00 & 0.00 & 0.00 & 1.12 & 0.74 & 0.00 & 0.00 & 0.00 & 0.00 & 0.00 & 39.97 & 0.00 \\
\hline 9 & 45.23 & 0.00 & 0.00 & 4.87 & 5.08 & 0.00 & 1.90 & 0.00 & 0.00 & 0.00 & 0.00 & 35.01 \\
\hline 10 & 45.23 & 0.00 & 0.00 & 3.67 & 0.00 & 0.19 & 0.00 & 0.00 & 4.66 & 0.00 & 0.00 & 48.54 \\
\hline II & 45.23 & 0.00 & 0.00 & 0.74 & 0.00 & 1.88 & 0.00 & 0.00 & 116.82 & 35.37 & 0.00 & 74.59 \\
\hline 12 & 0.00 & 0.00 & 0.00 & 2.86 & 0.00 & 0.00 & 0.00 & 0.00 & 86.10 & 0.00 & 0.00 & 47.86 \\
\hline 13 & 86.45 & 82.97 & 0.00 & 14.40 & 3.06 & 0.00 & 1.90 & 0.00 & 0.00 & 43.89 & 34.80 & 0.00 \\
\hline 14 & 0.00 & 0.00 & 0.00 & 4.67 & 0.00 & 0.00 & 0.00 & 0.00 & 0.00 & 48.20 & 42.42 & 0.00 \\
\hline 15 & 45.23 & 0.00 & 0.00 & 5.50 & 0.00 & 0.00 & 0.00 & 0.00 & 0.00 & 38.81 & 0.00 & 0.00 \\
\hline 16 & 104.53 & 91.08 & 0.00 & 94.63 & 17.21 & 0.00 & 26.57 & 2.55 & 0.00 & 55.63 & 44.65 & 42.85 \\
\hline 17 & 84.67 & 115.15 & 0.00 & 15.66 & 100.65 & 0.00 & 1.90 & 86.55 & 0.00 & 43.14 & 54.04 & 44.04 \\
\hline 18 & 0.00 & 69.72 & 0.00 & 0.00 & 1.88 & 0.00 & 0.00 & 6.54 & 0.00 & 0.00 & 45.58 & 40.01 \\
\hline 19 & 0.00 & 0.00 & 0.00 & 0.00 & 0.00 & 1.12 & 0.00 & 0.00 & 2.96 & 0.00 & 0.00 & 45.58 \\
\hline 20 & 0.00 & 0.00 & 0.00 & 0.00 & 0.00 & 0.00 & 0.00 & 0.00 & 0.00 & 0.00 & 44.19 & 47.69 \\
\hline 21 & 0.00 & 0.00 & 0.00 & 0.00 & 0.00 & 0.95 & 0.00 & 0.00 & 0.00 & 0.00 & 0.00 & 47.19 \\
\hline 22 & 0.00 & 0.00 & 0.00 & 0.00 & 0.00 & 0.00 & 0.00 & 0.00 & 4.66 & 0.00 & 44.65 & 60.77 \\
\hline 23 & 0.00 & 0.00 & 0.00 & 0.00 & 0.00 & 0.00 & 0.00 & 0.00 & 94.49 & 0.00 & 45.58 & 90.75 \\
\hline
\end{tabular}


Table I (Continued)

\begin{tabular}{|c|c|c|c|c|c|c|c|c|c|c|c|c|}
\hline \multirow[t]{2}{*}{ ID } & \multicolumn{3}{|l|}{ TNF- $\alpha$} & \multicolumn{3}{|l|}{ IL-I $\beta$} & \multicolumn{3}{|l|}{ IL-6 } & \multicolumn{3}{|l|}{ IL-8 } \\
\hline & $\mathbf{O h}$ & I h & $24 \mathrm{~h}$ & $\mathbf{O h}$ & I h & $24 \mathrm{~h}$ & O h & I h & $24 \mathrm{~h}$ & $\mathbf{O h}$ & I h & $24 \mathrm{~h}$ \\
\hline 24 & 0.00 & 0.00 & 0.00 & 0.00 & 0.00 & 0.00 & 0.00 & 0.00 & 0.00 & 0.00 & 38.23 & 0.00 \\
\hline 25 & 0.00 & 90.27 & 0.00 & 3.06 & 15.16 & 0.00 & 0.00 & 7.92 & 0.00 & 0.00 & 36.50 & 51.38 \\
\hline 26 & 69.72 & 106.95 & 0.00 & 7.63 & 98.42 & 0.00 & 6.88 & 86.09 & 0.00 & 0.00 & 53.26 & 56.86 \\
\hline 27 & 87.75 & 94.74 & 0.00 & 89.84 & 21.55 & 0.00 & 7.70 & 17.52 & 0.00 & 50.11 & 63.56 & 0.00 \\
\hline 28 & 0.00 & 0.00 & 116.62 & 0.00 & 0.00 & 106.34 & 0.00 & 0.00 & 22.22 & 0.00 & 0.00 & 78.76 \\
\hline 29 & 0.00 & 0.00 & 102.57 & 0.00 & 0.00 & 98.34 & 0.00 & 16.74 & 85.90 & 0.00 & 0.00 & 67.01 \\
\hline 30 & 0.00 & 106.68 & 82.30 & 0.00 & 91.76 & 10.33 & 0.00 & $|8.3|$ & 8.18 & 0.00 & 62.15 & 109.20 \\
\hline 31 & 0.00 & 129.16 & 0.00 & 0.00 & 110.28 & 0.00 & 0.00 & 86.89 & 0.00 & 0.00 & 69.61 & 51.56 \\
\hline 32 & 0.00 & 0.00 & 0.00 & 0.00 & 9.41 & 0.19 & 0.00 & 7.23 & 1.63 & 0.00 & 47.19 & 47.86 \\
\hline 33 & 0.00 & 0.00 & 0.00 & 0.00 & 0.00 & 0.37 & 0.00 & 0.00 & 8.18 & 35.37 & 41.85 & 49.58 \\
\hline 36 & 90.67 & 92.73 & 84.68 & 17.74 & 13.66 & 1.12 & 3.20 & 5.87 & 3.98 & 43.59 & 51.01 & 0.00 \\
\hline 37 & 91.48 & 125.50 & 91.95 & 22.40 & 101.32 & 0.00 & 19.90 & 87.88 & 2.96 & 48.20 & 69.08 & $4 I .15$ \\
\hline 38 & 0.00 & 83.92 & 91.12 & 1.88 & 7.20 & 0.00 & 0.00 & 0.00 & 2.63 & 0.00 & 0.00 & 0.00 \\
\hline 39 & 0.00 & 39.25 & 87.97 & 2.66 & 0.00 & 0.00 & 1.90 & 0.00 & 86.03 & 0.00 & 0.00 & 70.14 \\
\hline Mean \pm & $27.91 \pm$ & $43.06 \pm$ & $20.99 \pm$ & $11.26 \pm$ & $19.14 \pm$ & $9.06 \pm$ & $2.36 \pm$ & $15.53 \pm$ & $19.09 \pm$ & $15.49 \pm$ & $31.69 \pm$ & $44.10 \pm$ \\
\hline SD & 38.53 & 49.42 & 41.00 & 24.96 & 38.21 & 28.95 & 5.70 & 26.90 & 34.23 & 21.60 & 24.92 & 28.86 \\
\hline
\end{tabular}

Abbreviations: TNF- $\alpha$, tumor necrosis factor- $\alpha$; IL, interleukin; LASIK, laser in situ keratomileusis; PRK, photorefractive keratectomy; SD, standard deviation; h, hours.

the number of samples with a decreased concentration of this cytokine.

\section{Discussion}

In our study, concentrations of all the proinflammatory cytokines were detected and determined in a certain number of tear samples collected before excimer laser treatment. In the LASIK and PRK groups, TNF- $\alpha$ was detected in $26 \%$ (eight) and 38\% (14), IL-1 $\beta$ in 35\% (eleven) and 54\% (20), IL-6 in $16 \%$ (five) and $30 \%$ (eleven), and IL- 8 in 26\% (eight) and 35\% (13) of the samples, respectively. Participants with detected proinflammatory cytokines before excimer laser treatment (0 hours, control group) had no signs of ocular surface inflammation because the study included only healthy persons who

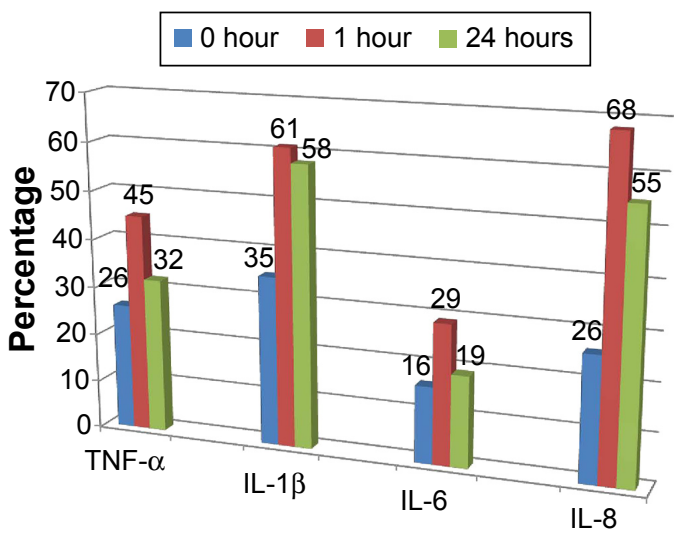

Figure I Percentages of samples with detectable concentration of proinflammatory cytokines (TNF- $\alpha$, IL-I $\beta$, IL-6, and IL-8).

Note: Tear samples were collected before (0 hours), I hour after, and 24 hours after LASIK treatment.

Abbreviations: TNF- $\alpha$, tumor necrosis factor- $\alpha$; IL, interleukin; LASIK, laser in situ keratomileusis. did not have any ocular or systemic disorders. Carreno et al determined the levels of 25 different cytokines and chemokines in tears of healthy subjects. Tears were drawn into capillary tubes and analyzed using multiplex bead-based assay. In this study, they report that these values can be used as control values to compare with the cytokine levels in tears collected from eyes with different ocular surface diseases. In their study, IL-1 $\beta$, IL-6, and IL- 8 were detected in $100 \%$ of the tear samples, and TNF- $\alpha$ in $50 \%$ of the tear samples from healthy subjects. ${ }^{11}$ VanDerMeid et al sampled tears from the eyes of healthy volunteers using Schirmer strips, and after analyzing the samples by the Luminex method, they detected IL- $1 \beta$, IL-6, IL- 8 , and TNF- $\alpha$ in more than $50 \%$ of the samples. ${ }^{12}$ From these reports, we can conclude that proinflammatory cytokines can also be

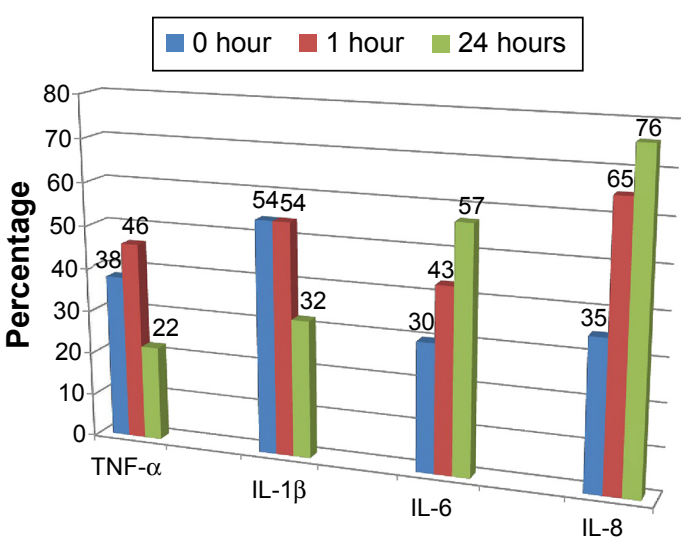

Figure 2 Percentages of samples with detectable concentration of proinflammatory cytokines (TNF- $\alpha$, IL-I $\beta$, IL-6, and IL-8).

Note: Tear samples were collected before ( 0 hours), I hour after, and 24 hours after PRK treatment.

Abbreviations: TNF- $\alpha$, tumor necrosis factor- $\alpha$; IL, interleukin; PRK, photorefractive keratectomy. 
Table 2 Statistical significance of differences in concentrations of proinflammatory cytokines (TNF- $\alpha$, IL-I $\beta$, IL-6, and IL-8) in tear samples with detectable cytokine values collected before treatment ( 0 hours, control), I hour after, and 24 hours after treatment by LASIK and PRK methods

\begin{tabular}{llll}
\hline Cytokine & $\begin{array}{l}\text { Time of tear } \\
\text { sample collection }\end{array}$ & $\begin{array}{l}\text { LASIK } \\
(\boldsymbol{P} \text {-value })\end{array}$ & $\begin{array}{l}\text { PRK } \\
(\boldsymbol{P} \text {-value })\end{array}$ \\
\hline TNF- $\alpha$ & $0 \mathrm{~h} / \mathrm{I} \mathrm{h}$ & $>0.05$ & $>0.05$ \\
& $0 \mathrm{~h} / 24 \mathrm{~h}$ & $>0.05$ & $>0.05$ \\
& $\mathrm{I}$ h/24 h & $>0.05$ & $0.042 \mathrm{I}^{*}$ \\
$\mathrm{IL}-\mathrm{I} \beta$ & $0 \mathrm{~h} / \mathrm{I} \mathrm{h}$ & $>0.05$ & $>0.05$ \\
& $0 \mathrm{~h} / 24 \mathrm{~h}$ & $>0.05$ & $>0.05$ \\
& $\mathrm{I} \mathrm{h} / 24 \mathrm{~h}$ & $>0.05$ & $0.0225^{*}$ \\
$\mathrm{IL}-6$ & $0 \mathrm{~h} / \mathrm{I} \mathrm{h}$ & $>0.05$ & $0.003 \mathrm{I}^{*}$ \\
& $0 \mathrm{~h} / 24 \mathrm{~h}$ & $>0.05$ & $0.0059^{*}$ \\
& $\mathrm{I} \mathrm{h} / 24 \mathrm{~h}$ & $>0.05$ & 0.05 \\
$\mathrm{IL}-8$ & $0 \mathrm{~h} / \mathrm{I} \mathrm{h}$ & $0.0007^{*}$ & $0.0006^{*}$ \\
& $0 \mathrm{~h} / 24 \mathrm{~h}$ & $0.003 \mathrm{I}^{*}$ & $0.0005^{*}$ \\
& $\mathrm{I} \mathrm{h} / 24 \mathrm{~h}$ & $>0.05$ & 0.05 \\
\hline
\end{tabular}

Note: *Statistically significant difference (Wilcoxon test).

Abbreviations: TNF- $\alpha$, tumor necrosis factor- $\alpha$; IL, interleukin; LASIK, laser in situ keratomileusis; PRK, photorefractive keratectomy; h, hours.

found in tears of healthy people. Almost 15 years ago, Thakur and Willcox described diurnal changes in tear cytokine values of healthy people. ${ }^{13}$ That is, switch of lacrimation process during the sleep period results in a significant increase of tear IgA; polymorphonuclear number; and IL-8, IL-6, and granulocyte macrophage colony-stimulating factor (GM-CSF) concentrations, which can be easily detected in the first samples taken after eye opening. This is one of the mechanisms responsible for the elimination of entrapped microorganisms, foreign particles, and dying or damaged cells.

Table 3 Statistical significance of differences in average concentration values of proinflammatory cytokines (TNF- $\alpha$, IL-I $\beta$, IL-6, and IL-8) in all tested samples between treatment groups, LASIK and PRK, at different time points

\begin{tabular}{lll}
\hline Cytokine & $\begin{array}{l}\text { Time of tear } \\
\text { sample collection }\end{array}$ & $\begin{array}{l}\text { LASIK vs PRK } \\
\text { (P-value) }\end{array}$ \\
\hline TNF- $\alpha$ & $0 \mathrm{~h} / \mathrm{I} \mathrm{h}$ & $>0.05$ \\
& $0 \mathrm{~h} / 24 \mathrm{~h}$ & $>0.05$ \\
$\mathrm{I} / 24 \mathrm{~h}$ & $>0.05$ \\
$\mathrm{IL}-\mathrm{I} \beta$ & $0 \mathrm{~h} / \mathrm{I} \mathrm{h}$ & $>0.05$ \\
& $0 \mathrm{~h} / 24 \mathrm{~h}$ & $>0.05$ \\
$\mathrm{IL}-6$ & $\mathrm{I} \mathrm{h} / 24 \mathrm{~h}$ & $0.0134^{*}$ \\
& $0 \mathrm{~h} / \mathrm{I} \mathrm{h}$ & $>0.05$ \\
& $0 \mathrm{~h} / 24 \mathrm{~h}$ & $>0.05$ \\
$\mathrm{IL}-8$ & $\mathrm{I} \mathrm{h} / 24 \mathrm{~h}$ & $0.003 \mathrm{I}^{*}$ \\
& $0 \mathrm{~h} / \mathrm{I} \mathrm{h}$ & $>0.05$ \\
& $0 \mathrm{~h} / 24 \mathrm{~h}$ & $>0.05$ \\
& $\mathrm{I} \mathrm{h} / 24 \mathrm{~h}$ & $>0.05$ \\
\hline
\end{tabular}

Note: *Statistically significant difference (Mann-Whitney test).

Abbreviations: TNF- $\alpha$, tumor necrosis factor- $\alpha$; IL, interleukin; LASIK, laser in situ keratomileusis; PRK, photorefractive keratectomy; h, hours.
Our study showed that during the acute phase of inflammation in corneal wound healing after LASIK, an increased production of proinflammatory cytokines can be seen. Also, our findings indicate that 24 hours after refractive treatment, there is a significantly larger concentration of IL-1 $\beta$ ( $P=0.0134)$ in tears after LASIK compared to PRK treatment. In addition, our results indicate that the acute phase of inflammation during corneal wound healing after PRK treatment is followed with an increased production of the following proinflammatory cytokines: TNF- $\alpha$, IL- 6 , and IL-8. Twenty-four hours after treatment, there was a significantly larger concentration of IL-6 ( $P=0.0031)$ in tears after PRK compared to LASIK treatment.

Leonardi et al examined levels of different cytokines and chemokines in tears of myopic eyes before and after LASIK, as well as in human corneal fibroblast cultures before and after excimer laser treatment. Tears were sampled with glass capillary micropipette from eyes of 15 myopic patients before, 1 hour after, and 24 hours after the LASIK procedure. Cytokine values in tear samples were determined by multiplex bead analysis. ${ }^{14}$ Regarding TNF- $\alpha$, the level of this cytokine in tear samples 1 hour after LASIK treatment was increased in seven of the 15 patients $(47 \%)$. In corneal fibroblast cultures, TNF- $\alpha$ was detected neither before nor after exposing of cultures to photoablation by excimer laser. ${ }^{14}$ Vesaluoma et al compared concentrations of TNF- $\alpha$ in tear samples before and after PRK. They sampled tears with scaled microcapillary tubes from the eyes of 18 patients at the following time points: preoperatively, on day 2 postoperatively, and on day 7 postoperatively. Concentrations of TNF- $\alpha$ in tear samples were determined using double antibody radioimmunoassay. The mean concentration of TNF- $\alpha$ in tear samples was as follows: preoperatively $358 \mathrm{ng} / \mathrm{L}(9.5 \mathrm{pg} / \mathrm{min})$, on day 2 postoperatively $417 \mathrm{ng} / \mathrm{L}$ (28.6 pg/min), and on day 7 postoperatively $320 \mathrm{ng} / \mathrm{L}$ (4.8 $\mathrm{pg} / \mathrm{min}$ ). These results show that TNF- $\alpha$ is present in the tear fluid of healthy people, and there is a significantly increased release of this cytokine in tears after PRK treatment, which suggests that TNF- $\alpha$ has a role in corneal wound healing after excimer laser treatment. ${ }^{15}$

As far as IL- $1 \beta$ is concerned, Leonardi et al found increased levels of this cytokine in six patients $(40 \%$ of samples) 1 hour after LASIK treatment. In corneal fibroblast cultures before excimer laser treatment, IL-1 $\beta$ was lower but still detectable. Twenty-four hours after exposing the cultures to photoablation by excimer laser, levels became significantly increased compared with the 1 hour time point. ${ }^{14}$ IL-1 is an important mediator of immune reactions, especially 
inflammation. There are two proinflammatory forms of this cytokine (IL-1 $\alpha$ and IL-1 $\beta$ ), and both forms produce similar biological effects. IL-1, among other things, stimulates the production of other proinflammatory cytokines such as TNF- $\alpha$, IL-6, and IL- $8 .{ }^{10}$ Netto and Wilson in their review note that in corneal epithelial and stromal wound healing, IL-1 plays an important role in apoptosis, metalloproteinase production, and increased cytokine production by keratocytes. ${ }^{6}$ Barbosa et al examined stromal expression of IL-1 after corneal injury followed with haze, similar to an injury caused by PRK treatment on rabbit corneas, and observed stromal expression of IL-1 as well as the occurrence of haze 4 weeks after treating corneas with an excimer laser. They showed that stromal fibroblasts, keratocytes, and inflammatory cells produce IL- $1 \alpha$ and IL- $1 \beta$ which consequently lead to myofibroblast apoptosis, particularly in regions of cornea with haze. ${ }^{16}$

In a study by Leonardi et al, IL-6 was not detected in patients' tear samples before LASIK treatment. Postoperatively ( 24 hours after LASIK treatment), in nine of the 15 patients $(60 \%)$, there was increased levels of IL- 6 in the tear samples. The IL-6 mean tear levels significantly correlated with the mean symptom score 1 hour after surgery. Corneal fibroblast culture contained high levels of IL-6 before excimer laser treatment. One hour after exposing the cultures to photoablation with excimer laser IL-6 levels became lower, and 24 hours after excimer laser treatment IL-6 levels were significantly increased compared with the levels both before and 1 hour after treatment. ${ }^{14}$ Alio and Javaloy reviewed the study of Leonardi et al and stated that the symptom score after LASIK treatment correlated only with IL-6 tear levels and that this cytokine is directly involved in the development of postsurgical inflammation and in the wound-healing process. ${ }^{17}$ Malecaze et al investigated the role of IL-6 in corneal wound healing after PRK treatment and measured IL-6 levels in tears of 12 myopic patients before and 24 hours after treatment. The range of PRK correction was from -1.50 to -6.0 diopters. They performed stromal photoablation on an Omnimed excimer laser $(\lambda=193 \mathrm{~nm})$, preceded with mechanical epithelial removal. They collected tear samples using microcapillary pipettes and measured the levels of IL-6, observing a statistically significant increase $(P<0.01)$ of IL-6 in tear samples 24 hours after treatment. Malecaze et al suggested that IL-6 might be regarded as a mediator involved in corneal healing after excimer laser treatment. ${ }^{18}$

According to Leonardi et al, IL-8 was the only cytokine consistently present in the tear samples in all the patients before LASIK treatment. Compared with the levels before surgery, IL-8 levels were significantly higher in the tear samples of eight of the 15 patients (53\%) 24 hours after surgery. Corneal fibroblast culture contained high levels of IL-8 before excimer laser treatment. One hour after exposing the cultures to photoablation with excimer laser, levels of IL-8 were reduced. But 24 hours after treatment, IL-8 levels were significantly increased compared to 1 hour after treatment. ${ }^{14}$ Alio and Javaloy suggested that IL-8 levels were significantly increased 24 hours after laser treatment, confirming that stimulated corneal fibroblasts produce this cytokine after injury. IL-8, produced by keratocytes and neutrophils, may stimulate the development of diffuse lamellar keratitis (Sands of Sahara) in an animal model as a noninfectious LASIK complication. ${ }^{17}$ Asano-Kato et al, in an animal model (rabbit eyes), showed that neutrophil infiltration and production of IL-8 by keratocytes and neutrophils are involved in experimentally induced diffuse lamellar keratitis. ${ }^{19}$ In our study, there was no occurrence of diffuse lamellar keratitis in LASIK-treated eyes.

Limitations of the study are a relatively small number of participants, a short time of postsurgical monitoring, and the role of post-procedure reflex tearing and its possible effect in dilution of the proinflammatory cytokines.

\section{Conclusion}

In conclusion, the acute phase of corneal wound healing after excimer laser treatment is defined by an intensive inflammatory response. After PRK treatment, there were increased concentrations of TNF- $\alpha$ and IL- $1 \beta$ in tear samples 1 hour after treatment, IL-6, 1 and 24 hours after treatment, and IL-8, 1 and 24 hours after treatment. After LASIK treatment, increased concentrations of IL- 8 were noted in tear samples 1 hour after treatment and IL-1 $\beta$, 24 hours after treatment. Both PRK and LASIK methods are characterized with a significant inflammatory response, distinctive by a different inflammatory cytokine profile. Also, tear findings following PRK method showed a more intensive inflammatory response than the findings after LASIK method. In an acute response to a locally produced injury, TNF- $\alpha$ might modify the expression of adhesion molecules and chemokine production, while IL-1 $\beta$ may mediate the elimination of damaged cells, most probably by inducing apoptosis. IL-8 is important in the regulation of neutrophil homing in injured cornea, and high locally available IL-6 could initiate early reparative processes, influencing change of local neutrophils and monocytes to reparative phenotypes (N2 and M2). Changes of proinflammatory cytokine levels in tears instantly following excimer laser treatment indicate 
that these cytokines take part in the corneal recovery process after corneal refractive surgery.

\section{Disclosure}

The authors report no conflicts of interest in this work.

\section{References}

1. Wilson SE, Netto M, Ambrosio R Jr. Corneal cells: chatty in development, homeostasis, wound healing, and disease. Am J Ophthalmol. 2003; 136:530-536.

2. Netto MV, Mohan RR, Ambrosio R, Hutcheon AEK, Zieske JD, Wilson SE. Wound healing in the cornea. Cornea. 2005;24:509-522.

3. Cameron JD. Corneal reaction to injury. In: Krachmer JH, Mannis MJ, Holland EJ, editors. Cornea. Philadelphia: Elsevier-Mosby; 2005: 115-132.

4. Wilson SE, Mohan Rahul R, Mohan Rajiv R, Ambrosio R Jr, Hong J, Lee J. The corneal wound healing response: cytokine-mediated interaction of the epithelium, stroma, and inflammatory cells. Prog Retin Eye Res. 2001;20:625-637.

5. Wilson SE, Liu JJ, Mohan Rajiv R. Stromal-epithelial interactions in the cornea. Prog Retin Eye Res. 1999;18:293-309.

6. Netto MV, Wilson SE. Indications for excimer laser surface ablation. $J$ Refract Surg. 2005;21:734-741.

7. Torres PF, Kijlstra A. The role of cytokines in corneal immunopathology. Ocular Immunol Inflamm. 2001;9:9-24.

8. Gilroy DW. Resolution of acute inflammation and wound healing. In: Serhan CN, Ward PA, Gilroy DW, editors. Fundamentals of Inflammation. New York: Cambridge University Press; 2010:17-27.

9. Lindell DM, Lukacs NW. Cytokines and chemokines in inflammation. In: Serhan CN, Ward PA, Gilroy DW, editors. Fundamentals of Inflammation. New York: Cambridge University Press; 2010:175-185.
10. Acera A, Rochaq G, Vecino E, Lema I, Duran JA. Inflammatory markers in the tears of patients with ocular surface disease. Ophthalmic Res. 2008; 40:315-321.

11. Carreno E, Enriquez-de-Salamanca A, Teson M, et al. Cytokine and chemokine levels in tears from healthy subjects. Acta Ophthalmol. 2010;88:250-258.

12. VanDerMeid KR, Su SP, Krenzer KL, Ward KW, Zhang JZ. A method to extract cytokines and matrix metalloproteinase from Schirmer strips and analyze using Luminex. Mol Vis. 2011;17:1056-1063.

13. Thakur A, Willcox M. Detection of cytokines in tears. In: O'Neill LAJ, Bowie A, editors. Methods in Molecular Medicine, Vol. 60: Interleukin Protocols. Totowa, NJ: Humana Press Inc.; 2001:345-353.

14. Leonardi A, Tavolato M, Curnow SJ, Fregona IA, Violato D, Alio JL. Cytokine and chemokine levels in tears and corneal fibroblast cultures before and after excimer laser treatment. J Cataract Refract Surg. 2009; 35:240-247.

15. Vesaluoma M, Teppo AM, Gronhagen-Riska C, Tervo T. Increased release of tumor necrosis factor- $\alpha$ in human tear fluid after excimer laser induced corneal wound. Br J Ophthalmol. 1997;81:145-149.

16. Barbosa FL, Chaurasia S, Kaur H, de Medeiros FW, Agrawal V, Wilson SE. Stromal interleukin-1 expression in the cornea after haze associated injury. Exp Eye Res. 2010;91:456-461.

17. Alio JL, Javaloy J. Corneal inflammation following corneal photoablative refractive surgery with excimer laser. Surv Ophthalmol. 2013;58: $11-25$.

18. Malecaze F, Simorre V, Chollet $P$, et al. Interleukin-6 in tear fluid after photorefractive keratectomy and its effects on keratocytes culture. Cornea. 1997;16:580-587.

19. Asano-Kato N, Toda I, Shimmura S, et al. Detection of neutrophils and possible involvement of interleukin- 8 in diffuse lamellar keratitis after laser in situ keratomileusis. J Cataract Refract Surg. 2003;29: 1996-2000.
Clinical Ophthalmology

\section{Publish your work in this journal}

Clinical Ophthalmology is an international, peer-reviewed journal covering all subspecialties within ophthalmology. Key topics include: Optometry; Visual science; Pharmacology and drug therapy in eye diseases; Basic Sciences; Primary and Secondary eye care; Patient Safety and Quality of Care Improvements. This journal is indexed on

\section{Dovepress}

PubMed Central and CAS, and is the official journal of The Society of Clinical Ophthalmology (SCO). The manuscript management system is completely online and includes a very quick and fair peer-review system, which is all easy to use. Visit http://www.dovepress.com/ testimonials.php to read real quotes from published authors. 